\title{
Consumption of fried foods and risk of coronary heart disease: Spanish cohort of the European Prospective Investigation into Cancer and Nutrition study
}

Pilar Guallar-Castillón associate professor ${ }^{12}$, Fernando Rodríguez-Artalejo professor ${ }^{12}$, Esther Lopez-Garcia assistant professor ${ }^{12}$, Luz M León-Muñoz postdoctoral research fellow ${ }^{12}$, Pilar Amiano

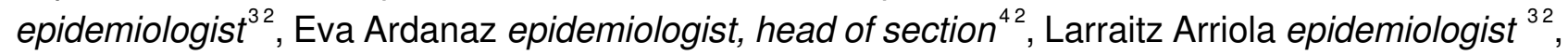
Aurelio Barricarte epidemiologist, head of service ${ }^{42}$, Genevieve Buckland nutritional epidemiologist ${ }^{6}$, María-Dolores Chirlaque specialist in preventive medicine and public health ${ }^{72}$, Miren Dorronsoro unit chief $^{32}$, José-María Huerta research associate ${ }^{72}$, Nerea Larrañaga epidemiologist ${ }^{32}$, Pilar Marin registered nurse ${ }^{42}$, Carmen Martínez senior scientist ${ }^{92}$, Esther Molina research associate ${ }^{92}$, Carmen Navarro senior scientist, head of department ${ }^{728}$, J Ramón Quirós epidemiologist ${ }^{10}$, Laudina Rodríguez medical doctor ${ }^{10}$, María José Sanchez professor and director of research ${ }^{92}$, Carlos A González senior scientist, unit chief ${ }^{6}$, Conchi Moreno-Iribas epidemiologist ${ }^{245}$

\footnotetext{
${ }^{1}$ Department of Preventive Medicine and Public Health, School of Medicine, Autonomous University of Madrid, 28029 Madrid, Spain; ${ }^{2} \mathrm{ClBER}$ de Epidemiología y Salud Pública, Spain; ${ }^{3}$ Public Health Division of Gipuzkoa, Instituto Investigación IIS BioDonostia, Basque Government, Donostia, Spain; ${ }^{4}$ Public Health Institute of Navarra, Pamplona, Spain; ${ }^{5}$ Department of Pediatrics, Department of Obstetrics and Gynecology, and Preventive Medicine, Autonomous University of Barcelona, Barcelona, Spain; ${ }^{6}$ Unit of Nutrition, Environment and Cancer, Cancer Epidemiology Research Programme, Catalan Institute of Oncology, Hospitalet de Llobregat, Barcelona, Spain; ${ }^{7}$ Department of Epidemiology, Murcia Regional Health Council, Spain; ${ }^{8}$ Department of Public Health and Preventive Medicine, University of Murcia, Spain; ${ }^{9}$ Andalusian School of Public Health, Granada, Spain; ${ }^{10}$ Public Health and Health Planning Directorate, Oviedo, Asturias, Spain
}

\author{
Abstract \\ Objective To assess the association between consumption of fried foods \\ and risk of coronary heart disease. \\ Design Prospective cohort study. \\ Setting Spanish cohort of the European Prospective Investigation into \\ Cancer and Nutrition. \\ Participants 40757 adults aged 29-69 and free of coronary heart \\ disease at baseline (1992-6), followed up until 2004. \\ Main outcome measures Coronary heart disease events and vital \\ status identified by record linkage with hospital discharge registers, \\ population based registers of myocardial infarction, and mortality \\ registers. \\ Results During a median follow-up of 11 years, 606 coronary heart \\ disease events and 1135 deaths from all causes occurred. Compared \\ with being in the first (lowest) quarter of fried food consumption, the \\ multivariate hazard ratio of coronary heart disease in the second quarter \\ was 1.15 (95\% confidence interval 0.91 to 1.45$)$, in the third quarter was
}

1.07 (0.83 to 1.38 ), and in the fourth quarter was 1.08 (0.82 to $1.43 ; P$ for trend 0.74$)$. The results did not vary between those who used olive oil for frying and those who used sunflower oil. Likewise, no association was observed between fried food consumption and all cause mortality: multivariate hazard ratio for the highest versus the lowest quarter of fried food consumption was 0.93 (95\% confidence interval 0.77 to 1.14 ; $P$ for trend 0.98).

Conclusion In Spain, a Mediterranean country where olive or sunflower oil is used for frying, the consumption of fried foods was not associated with coronary heart disease or with all cause mortality.

\section{Introduction}

Frying is one of the most commonly used methods for cooking in Western countries. When food is fried its nutritional content changes - the food loses water and takes up fat, increasing its energy density. ${ }^{12}$ Frying modifies both the foods and the frying medium because oils deteriorate during frying, especially when reused, through the processes of oxidation and hydrogenation, 
leading to a loss of unsaturated fats and an increase in trans fats. ${ }^{1}$ Thus fried food absorbs degradation products of the frying oil. ${ }^{3}$ At the same time, frying may also improve palatability by making food crunchy. ${ }^{45}$

Fried foods have been associated with various cardiovascular risk factors in cross sectional studies. In Spain, the Pizarra study of 1226 adults showed that consumption of food fried with reused oils was associated with a higher prevalence of arterial hypertension. ${ }^{6}$ Furthermore, a cross sectional analysis of the Spanish cohort of the European Prospective Investigation into Cancer and Nutrition (EPIC) study concluded that consumption of fried foods was positively associated with general and central obesity. ${ }^{7}$ Similarly, in the SUN (Seguimiento University of Navarra) cohort in Spain, more frequent consumption of fried foods at baseline was associated with a higher risk of becoming overweight or obese during a six year follow-up. ${ }^{8}$ Lastly, in another cross sectional study in 2090 Italian adults, consumption of fried food was associated with lower high density lipoprotein cholesterol levels and a larger waist circumference. ${ }^{9}$

Only a few studies have evaluated the effect of fried foods on risk of cardiovascular disease. A case-control study in Costa Rica found no association between consumption of fried foods and risk of non-fatal acute myocardial infarction. ${ }^{10}$ Another case-control study, INTERHEART, observed a positive association between fried foods and acute myocardial infarction. ${ }^{11}$

Therefore, although interest in the associations of dietary patterns and specific cooking techniques with risk of disease is increasing, ${ }^{12}$ little is known about the health effects of fried foods. We evaluated prospectively the association between consumption of fried foods and the risk of coronary heart disease in the EPIC-Spain cohort.

\section{Methods}

The methods of the EPIC project have been reported elsewhere. ${ }^{73-16}$ For the present analysis we used the data from the Spanish cohort of EPIC, which included 41438 healthy adults (15 632 men), aged 29-69. Study participants were recruited between 1992 and 1996 in five Spanish regions. Three of these regions are located in the north (Asturias, Gipuzkoa, and Navarra) and two in the south, including the Mediterranean shore (Granada and Murcia). Selection of these regions aimed to maximise variability in diet because food and nutrient intake has traditionally been different between the north and the south of Spain and between the inner regions and coastal areas. To increase variability in diet, participants were also recruited in urban and rural areas from various educational and social sectors. Study participants included mostly blood donors, civil servants, and the general population. Participation rates varied from $55 \%$ to $60 \%$ between regions. The exposures of interest were assessed at baseline, and participants were followed up until 31 December 2004. All participants gave written informed consent before enrolment.

\section{Assessment of food consumption}

Using a computerised dietary history questionnaire, ${ }^{17}$ previously validated in Spain ${ }^{18-20}$ and administered by trained interviewers, we obtained data on usual food consumption for each participant. We used household measures, standard units, and a collection of 35 sets of photographs of simple foods, mixed foods, and drinks to quantify the portion of each food (g/day) consumed. Each interview on dietary history lasted about 40-50 minutes.
Participants were asked about food consumed in a typical week during the previous 12 months. Foods consumed at least twice a month were recorded. The dietary history questionnaire recorded information on up to 662 different foods, including those consumed individually and those consumed as part of 203 recipes and regional dishes. Of these foods, 212 were fried. We calculated energy and nutrient intake using the EPIC food composition table. ${ }^{21}$

Information on cooking methods was collected as part of the dietary history questionnaire. The same food may be cooked by several methods as part of a single recipe. For example, in the preparation of paella (a typical Spanish recipe), rice is both fried and boiled. Thus, fried food was defined as food for which frying was the only cooking method used. Such food could be deep fried or pan fried and it could be battered, crumbed, or sautéed. To estimate the absorption of fat from frying, we used an absorption coefficient for each fried food. ${ }^{18} \mathrm{We}$ also recorded the type of oil used for dressing, cooking, and frying.

\section{Assessment of non-dietary variables}

Information on demographic variables, educational level, smoking, and physical activity was obtained through interview at recruitment. Physical activity was assessed with a validated questionnaire that included activity at work, at home, and during leisure time. ${ }^{22}$ Participants were also asked if they had diabetes mellitus, hypercholesterolaemia, hypertension, cancer, or angina, or had experienced myocardial infarction or stroke. In addition they were asked to report their menopausal status and any use of oral contraceptives or hormone replacement therapy. Trained observers used standardised procedures to measure weight, height, and waist circumference. The body mass index was calculated as weight $(\mathrm{kg})$ divided by height squared $\left(\mathrm{m}^{2}\right)$.

\section{Ascertainment and validation of coronary heart disease}

At baseline, prevalent coronary heart disease was self reported. During follow-up, we ascertained incident coronary heart disease with a telephone questionnaire (at three years after recruitment) and through record linkage with three sources of information: hospital discharge databases, population based myocardial infarction registries (available in Murcia, Navarra, and Gipuzkoa), and regional mortality registries and the national mortality database (managed by the National Statistical Institute, Madrid, Spain), which provided information on date and cause of death.

Coronary heart disease was classified according to the International Classification of Diseases, ninth revision (ICD-9 codes 410-414) and 10th revision (ICD-10 codes I20-I25). A team of trained doctors and nurses validated coronary heart disease events against hospital records and autopsy reports.

Coronary heart disease events were classified on the basis of symptoms, signs, biomarkers, and findings on electrocardiogram or at autopsy, according to standard criteria. ${ }^{23}$ A definite coronary heart disease event was defined as one meeting all relevant criteria for a fatal or non-fatal acute myocardial infarction, or angina requiring revascularisation (coronary artery bypass graft or percutaneous transluminal coronary angioplasty). We defined probable and possible acute coronary heart disease events as cases where electrocardiogram findings were non-specific or the biomarkers were equivocal or missing. ${ }^{13}$

\section{Statistical analysis}

Of the 41438 participants in the cohort, we excluded the following from the analyses: 193 for having coronary heart 
disease at baseline; 167 for an implausibly high or low dietary consumption, defined as 3 standard deviations either way from the cohort mean ( $<788 \mathrm{kcal} /$ day or $>5710 \mathrm{kcal} /$ day $)$; and 321 for lacking data on important variables such as date of coronary heart disease event $(n=12)$, smoking $(n=22)$, diabetes mellitus $(\mathrm{n}=71)$, hypercholesterolaemia $(\mathrm{n}=197)$, and hypertension $(n=60)$. Thus the analyses were carried out on 40757 participants.

We used Cox regression to obtain hazard ratios for coronary heart disease according to sex specific quarters of fried food consumption. The quarter (first) with lowest consumption was used as reference. In the Cox models, age was the underlying time variable, with entry time defined as the participant's age at recruitment and exit time as the age at the coronary heart disease event, death, or 31 December 2004, whichever came first. To reduce violations of the proportional hazards assumption we also stratified models by age at recruitment (five year groups), sex, and centre. We built three models, with progressive adjustment for potential confounders to determine their influence on the results. Model 1 was adjusted for energy intake and model 2 was additionally adjusted for educational level, smoking, physical activity (at work, at home, and during leisure time), diabetes mellitus, hyperlipidaemia, cancer, oral contraceptive use, menopause, hormone replacement therapy, ethanol intake, and consumption of non-fried foods (vegetables, fruits, nuts, dairy products, meat, and fish). Model 3 was additionally adjusted for possible mediators of the study association reported in the literature: body mass index, waist circumference, and hypertension. We categorised continuous variables into quarters, except for age, which was analysed as a continuous variable. The $\mathrm{P}$ for linear trend was calculated by modeling the quarters for fried food as a continuous variable. Moreover, we also calculated hazard ratios of coronary heart disease and of all cause mortality for a $100 \mathrm{~g}$ increase in fried food consumption analysed as a continuous variable.

New analyses were done after censoring the first two years of follow-up and after excluding those who reported a change in their diet during the previous year. To test whether the study association varied with type of oil used for frying (olive oil versus sunflower oil or other vegetable oils), we used the likelihood ratio test, which compared models with and without interaction terms (products of the quarters for fried food and type of oil). We also used the same procedure to test whether results varied by sex.

Statistical significance was set at $\mathrm{P}<0.05$. The analyses were carried out with SAS, version 9.1 for Windows. This manuscript follows the recommendations of the Strengthening the Reporting of Observational Studies in Epidemiology (STROBE) initiative. $^{24}$

\section{Results}

An average $138 \mathrm{~g}$ of fried food was consumed daily, including $14 \mathrm{~g}$ of oil used for frying. About $7 \%$ of the total amount of food consumed was fried. Fried food consumption ranged from 0-817 g/day for men and 0-657 g/day for women. Sixty two per cent of participants used olive oil for frying and the rest used sunflower oil or other vegetable oils.

Participants with a higher fried food intake were younger, of a higher level of education, more often smokers, and less often sedentary at work (table $1 \Downarrow$ ). Moreover, they had a lower prevalence of diabetes mellitus and hyperlipidaemia, a higher energy and ethanol intake, and a lower consumption of non-fried vegetables, fruit, dried fruit and nuts, milk products, and non-fried fish (table $2 \Downarrow$ ). They also had a lower frequency of diagnosed hypertension. Among women, the frequency of menopausal status decreased with the consumption of fried food (table 2).

During a median follow-up of 11 years, 606 definite coronary heart disease events occurred (466 myocardial infarctions and 140 anginas requiring revascularisation). There were also 712 definite, possible, or probable coronary heart disease events and 1135 deaths from all causes.

For definite coronary heart disease events, no association with fried food consumption was observed in analyses adjusting for energy intake, age, sex, and centre (table $3 \Downarrow$, model 1 ). The hazard ratio of coronary heart disease for the highest versus the lowest quarter of fried food consumption was $0.94(95 \%$ confidence interval 0.72 to 1.23 ; $P$ for trend 0.52 ). Similar results were obtained after additional adjustment for the main confounders (table 3, model 2): 1.11 (0.84 to 1.46; P for trend $0.60)$. Finally, no association was observed between fried food and incident coronary heart disease after adjusting for possible mediators such as body mass index, waist circumference, and hypertension (table 3, model 3). Compared with the first (lowest) quarter of fried food consumption, the multivariate hazard ratios of coronary heart disease were $1.15(0.91$ to 1.45$)$ in the second quarter, 1.07 (0.83 to 1.38) in the third quarter, and 1.08 (0.82 to 1.43 ) in the fourth quarter ( $\mathrm{P}$ for trend 0.74 ). Lastly, after full adjustment, a $100 \mathrm{~g}$ increase in the consumption of fried food did not show an association with risk of coronary heart disease (hazard ratio $1.00,0.90$ to 1.11 ). The results were similar after censoring the first two years of follow-up and after excluding those who reported a change in their diet during the previous year. The results did not vary between those who used olive oil for frying and those who used sunflower oil or other vegetable oils ( $\mathrm{P}$ for interaction 0.22 ), or between the sexes ( $\mathrm{P}$ for interaction 0.19).

Similar results were also obtained in the combined analysis of definite, possible, and probable coronary heart disease events. Compared with the first (lowest) quarter of fried food consumption, the multivariate hazard ratio of coronary heart disease in the fully adjusted model (model 3$)$ was 1.08 (0.88 to 1.34) for the second quarter, 1.06 (0.84 to 1.33) for the third quarter, and 1.04 (0.81 to 1.34 ) for the fourth quarter ( $\mathrm{P}$ for trend 0.83 ).

Fried food consumption also failed to be associated with all cause mortality. Compared with the lowest quarter of fried food consumption, those in the highest quarter had a hazard ratio of 0.93 (0.77 to 1.14; P for trend 0.98). Moreover, no association was observed between a $100 \mathrm{~g}$ increase in intake of fried food and total mortality (1.00, 0.92 to 1.08; table 3, model 3).

Of the total amount of fried food consumed, 24\% (34 g/day) was fish, $22 \%$ (31 g/day) meat, $21 \%$ (30 g/day) potatoes, and $11 \%$ (15 g/day) eggs. No association was observed between each of these fried food groups and incident coronary heart disease (table $4 \Downarrow$ ). Comparing the highest and lowest quarters, the multivariate hazard ratio for the fully adjusted model was 1.13 (0.89 to 1.44; P for trend 0.26) for fried fish, 1.09 (0.82 to 1.43; $\mathrm{P}$ for trend 0.32$)$ for fried meat, $0.90(0.70$ to 1.15 ; $\mathrm{P}$ for trend 0.45 ) for fried potatoes, and 0.87 ( 0.68 to 1.13 ; $P$ for trend $0.30)$ for fried eggs. These fried foods also failed to show an association with all cause mortality (table 4).

\section{Discussion}

This analysis of the Spanish cohort of the European Prospective Investigation into Cancer and Nutrition found no association between consumption of fried food and risk of coronary heart disease or all cause mortality. 


\section{Comparison with other studies}

Few studies have evaluated this association. Our results are consistent with those of a case-control study of non-fatal myocardial infarction in Costa Rica, which obtained an odds ratio of 1.06 ( 0.59 to 1.91 ; $\mathrm{P}$ for trend 0.65$)$ for the highest versus lowest fifth of fried food consumption. ${ }^{10}$ However, in the Costa Rican investigation, palm and partially hydrogenated soy oil were used for frying, whereas in this study mainly olive and sunflower oils - the most commonly used oils in Mediterranean countries-were used.

Our results differ from those of the INTERHEART study, where fried food consumption was associated with a higher risk of acute myocardial infarction. ${ }^{11}$ However, some methodological differences limit the comparison of results. For instance, INTERHEART did not assess quantitatively the intake of fried food; moreover, it recorded the consumption of only nine fried foods and it did not report the type of oil used for frying.

In a cross sectional analysis of the Multi Ethnic Study of Atherosclerosis (MESA), no association was found between consumption of fried fish and subclinical atherosclerosis, assessed by the thickness of intima-media in the common carotid. Nor was fried fish consumption associated with significant changes in serum levels of total cholesterol, low density lipoprotein cholesterol, high density lipoprotein cholesterol, or tryglicerides. ${ }^{25}$ The Cardiovascular Health Study, a cohort of 3919 older people ( $\geq 65$ years) followed for nine years, also did not find an association of consumption of fried fish or fish sandwiches with mortality from coronary heart disease or cardiac arrhythmia, or with incidence of non-fatal acute myocardial infarction. ${ }^{26}$

\section{Possible mechanisms of the study association}

The frying process is complex and as yet is not well understood. Laboratory investigations show that fried foods may act through many mechanisms, such that the resulting effect on coronary heart disease is difficult to anticipate. Frying changes the quality and composition of food. For example, frying usually augments the fat content, and for some foods, such as potatoes, the dietary fibre is increased owing to the formation of resistant starch. ${ }^{1}$ Frying can specifically increase the amount of trans fatty acids in foods. ${ }^{27}$ The amount depends on the frying technique (deep or pan frying), the degree of thermal degradation of the oil, the type of food, and, above all, the type of oil (the degree of oil unsaturation increases the formation of trans fatty acids). ${ }^{28}$ However, some foods such as certain types of fish show minimal variations in the content of trans fatty acids after frying, regardless of whether olive oil or sunflower oil is used. ${ }^{29}$ On the other hand, the use of solid fats for frying can also increase the content of trans fatty acids.

The association between consumption of fried foods and endothelial damage is controversial. In a cross sectional analysis of the Multi Ethnic Study of Atherosclerosis (MESA), consumption of fried fish was inversely associated with the level of soluble intercellular adhesion molecule-1, a marker of endothelial activation. The authors did not expect this finding, since it was not observed for consumption of non-fried fish. ${ }^{30}$ In contrast, meals rich in oils previously used for deep frying in fast food restaurants have been associated with endothelial damage. ${ }^{31}$ In another study, however, foods rich in oils previously used for frying and high in oxidation products increased postprandial triglyceridaemia but did not affect endothelial function. ${ }^{32}$
Other mechanisms may be operating during the frying process. For example, in an in vitro study fried eggs increased the production of angiotensin converting enzyme inhibitory peptides more than boiled eggs did. ${ }^{33}$ On the other hand, frying also increases the levels of cholesterol oxidation products ${ }^{34}$ and reduces paraoxonase activity, an enzyme that inhibits oxidation of low density lipoprotein cholesterol. ${ }^{35}$

This analysis of the EPIC-Spain cohort suggests that the above mentioned mechanisms may offset each other in the general population, with the result that frying with mainly olive oil or sunflower oil is not associated with a higher risk of coronary heart disease. Frying with other types of fats may still be harmful.

\section{Limitations and strengths of the study}

This study has some limitations. Firstly, diet was measured only at baseline. Secondly, some residual confounding cannot be ruled out, since diabetes mellitus, hypertension, and hypercholesterolaemia were self reported. In Spain, however, evidence exists of the diagnostic validity of self reported diabetes mellitus and hypertension. ${ }^{3677}$ Thirdly, some degree of under-reporting of fried food consumption is possible, given that people perceive it as unhealthy; and non-differential under-reporting would bias the hazard ratio towards 1, hiding a possible association. Fourthly, we do not know the type of frying procedure (deep or pan) carried out, the extent that oils were reused, and the time and temperature used for frying. It is possible that these factors are differentially associated with coronary heart disease. Fifthly, we cannot separate the effect of a specific food from the effect of the cooking method used. For instance, we cannot separate the effect of frying with oil (for example, olive oil) from the cardioprotective effect of omega 3 fatty acids in fish. Sixthly, results are based on what people ate between 1992 and 1996. Unfortunately, since then no studies have been published on the consumption of fried food by the Spanish population. Data from household consumption surveys, however, indicate that the macronutrient intake has not changed materially from 1991 to $2006^{38}$; also, overall adherence to the Mediterranean pattern seems fairly stable in the period 1998 to $2005,{ }^{39}$ although an increase in the consumption of non-alcoholic beverages and dairy products and a decrease in consumption of potatoes and legumes has been observed over the past two decades. ${ }^{38}$ Finally, although average consumption of fried food in the highest quarter was fairly high, our results cannot rule out that a fried food intake higher than that observed in this study is associated with coronary heart disease.

This analysis also has important strengths, such as the use of a validated dietary history with quantitative information on the consumption of a large number of fried foods, the large sample size, long follow-up, and adjustment for numerous potential confounders.

\section{Conclusions}

In a Mediterranean country where olive and sunflower oils are the most commonly used fats for frying, and where large amounts of fried foods are consumed both at and away from home, no association was observed between fried food consumption and the risk of coronary heart disease or death.

Our results are directly applicable only to Mediterranean countries with frying methods similar to those in Spain. Firstly, oil (mainly olive and sunflower) rather than solid fat is used for frying in Spain. It is well established that olive oil is less prone to oxidation than other edible oils or fats. ${ }^{40}$ Secondly, consumption of fried foods in Spain is not a proxy for fast food 
intake. Fast foods are generally prepared by deep frying with oils used several times, and are consumed mostly away from home. In Spain, fried foods are consumed both at and away from home, and both deep frying and pan frying are used. Moreover, we can assume that oil is not reused many times for foods consumed at home; however, the cardiovascular effects of food fried with overly reused oils merit further research. Finally, consumption of fried snacks high in salt is fairly low in Spain, whereas in other countries such as the United States they provide an important percentage of energy intake. ${ }^{42}$

\section{Contributors: $\mathrm{CM}-\mathrm{I}$ is coordinator of the European Prospective} Investigation of Cancer and Nutrition (EPIC)-HEART-Spain. CAG is coordinator of the EPIC-Spain. CM-I and CAG contributed equally to the study. PG-C and FR-A conceived the study and drafted the manuscript. They are the guarantors. PG-C, FR-A, EL-G and LML-M analysed the data. PA, EA, LA, AB, GB, M-DC, MD, J-MH, NL, PM, $\mathrm{CM}, \mathrm{EM}, \mathrm{CN}, \mathrm{JRQ}, \mathrm{LR}$, and MJS provided the original data and information on the respective populations and helped design and analyse the study. AB, MD, CN, JRQ, MJS, and CAG were the principal investigators for EPIC. All authors interpreted the results and contributed to writing the manuscript and take responsibility for the integrity of the data and the accuracy of the data analysis.

Funding: This study was funded by research grants from FIS (PI04-0257, PI06-0366, PI04-2342, PI04-1822, PI04-1821, PI04-2188, and PI08-0166); RETIC (RD06/0020) of the Instituto de Salud Carlos III; and funds from the Spanish regional governments of Andalusia, Asturias, Basque Country, Murcia, and Navarra, and the Catalan Institute of Oncology. EL-G has a Ramón y Cajal contract from the Ministry of Education. Authors of this report, and not the funding agencies, are responsible for its content. The funder did not have any role in the study design; collection, analysis, and interpretation of the data; the writing of the report; and the decision to submit the article for publication.

Competing interests: All authors have completed the ICMJE uniform disclosure form at www.icmje.org/coi_disclosure.pdf (available on request from the corresponding author) and declare: no support from any organisation for the submitted work; no financial relationships with any organisations that might have an interest in the submitted work in the previous three years; and no other relationships or activities that could appear to have influenced the submitted work.

Ethical approval: This study was approved by the ethics committees of the International Agency for Research on Cancer (Lyon, France) and Bellvitge Hospital (Barcelona, Spain).

Data sharing: No additional data available.

1 Fillion L, Henry CJ. Nutrient losses and gains during frying: a review. Int J Food Sci Nutr 1998:49:157-68

2 Pokorn J, Panek J, Trojakova L. Effect of food component changes during frying on the nutrition value of fried food. Forum Nutr 2003:56:348-50

3 Sanchez-Muniz FJ, Cuesta C, Garrido-Polonio MC. Evaluation of a sunflower oil used for frying by different analytical indexes and column and gas chromatography. $Z$ Ernahrungswiss 1994;33:16-23.

4 Samra RA. Fats and satiety. In: Montmayeur JP, le Coutre J, eds. Fat detection: taste, texture, and post ingestive effects. CRC Press, 2010

5 Drewnowski A, Almiron-Roig E. Human perception and preferences for fat-rich foods. In: Montmayeur JP, le Coutre J, eds. Fat detection: taste, texture, and post ingestive effects. CRC Press, 2010.

6 Soriguer F, Rojo-Martinez G, Dobarganes MC, Garcia Almeida JM, Esteva I, Beltran M, et al. Hypertension is related to the degradation of dietary frying oils. Am J Clin Nutr 2003;78:1092-7.

7 Guallar-Castillon P, Rodriguez-Artalejo F, Fornes NS, Banegas JR, Etxezarreta PA, Ardanaz E, et al. Intake of fried foods is associated with obesity in the cohort of Spanish adults from the European Prospective Investigation into Cancer and Nutrition. Am J Clin Nutr 2007;86:198-205

8 Sayon-Orea C, Bes-Rastrollo M, Basterra-Gortari FJ, Beunza JJ, Guallar-Castillon P, de la Fuente-Arrillaga $\mathrm{C}$, et al. Consumption of fried foods and weight gain in a Mediterranean cohort: the SUN project. Nutr Metab Cardiovasc Dis 2011: published online 6 Aug.

9 Donfrancesco C, Lo NC, Brignoli O, Riccardi G, Ciccarelli P, Dima F, et al. Italian network for obesity and cardiovascular disease surveillance: a pilot project. BMC Fam Pract 2008;9:53.

10 Kabagambe EK, Baylin A, Siles X, Campos H. Individual saturated fatty acids and nonfatal acute myocardial infarction in Costa Rica. Eur J Clin Nutr 2003;57:1447-57.
11 Iqbal R, Anand S, Ounpuu S, Islam S, Zhang X, Rangarajan S, et al. Dietary patterns and the risk of acute myocardial infarction in 52 countries: results of the INTERHEART study. Circulation 2008;118:1929-37.

12 Astrup A, Dyerberg J, Elwood P, Hermansen K, Hu FB, Jakobsen MU, et al. The role of reducing intakes of saturated fat in the prevention of cardiovascular disease: where does the evidence stand in 2010? Am J Clin Nutr 2011;93:684-8.

13 Danesh J, Saracci R, Berglund G, Feskens E, Overvad K, Panico S, et al. EPIC-Heart: the cardiovascular component of a prospective study of nutritional, lifestyle and biological factors in 520,000 middle-aged participants from 10 European countries. Eur J Epidemiol 2007;22:129-41.

14 Riboli E, Kaaks R. The EPIC project: rationale and study design. European Prospective Investigation into Cancer and Nutrition. Int J Epidemiol 1997;26(suppl 1):S6-14.

15 Bingham S, Riboli E. Diet and cancer-the European Prospective Investigation into Cancer and Nutrition. Nat Rev Cancer 2004:4:206-15.

16 Riboli E, Hunt KJ, Slimani N, Ferrari P, Norat T, Fahey M, et al. European Prospective Investigation into Cancer and Nutrition (EPIC): study populations and data collection. Public Health Nutr 2002;5:1113-24.

17 Burke BS. The dietary history as a tool in research. J Am Diet Assoc 1947;23:104-11.

18 EPIC group of Spain. Relative validity and reproducibility of a diet history questionnaire in Spain. II. Nutrients. EPIC Group of Spain. European Prospective Investigation into Cancer and Nutrition. Int J Epidemiol 1997;26(suppl 1):S100-9.

19 EPIC group of Spain. Relative validity and reproducibility of a diet history questionnaire in Spain. I. Foods. EPIC Group of Spain. European Prospective Investigation into Cancer and Nutrition. Int J Epidemiol 1997;26(suppl 1):S91-9.

20 EPIC group of Spain. Relative validity and reproducibility of a diet history questionnaire in Spain. III. Biochemical markers. EPIC Group of Spain. European Prospective Investigation into Cancer and Nutrition. Int J Epidemiol 1997;26(suppl 1):S110-7.

21 Slimani N, Torrent M, Farrioll N. European Prospective Investigation into Cancer and Nutrition (EPIC): food composition tables-Spain. International Agency for Research on Cancer, 1991.

22 Haftenberger M, Schuit AJ, Tormo MJ, Boeing H, Wareham N, Bueno-de-Mesquita HB, et al. Physical activity of subjects aged 50-64 years involved in the European Prospective Investigation into Cancer and Nutrition (EPIC). Public Health Nutr 2002:5:1163-76.

23 Luepker RV, Apple FS, Christenson RH, Crow RS, Fortmann SP, Goff D, et al. Case definitions for acute coronary heart disease in epidemiology and clinical research studies: a statement from the AHA Council on Epidemiology and Prevention; AHA Statistics Committee; World Heart Federation Council on Epidemiology and Prevention; the European Society of Cardiology Working Group on Epidemiology and Prevention; Centers for Disease Control and Prevention; and the National Heart, Lung, and Blood Institute. Circulation 2003;108:2543-9.

24 Von Elm E, Altman DG, Egger M, Pocock SJ, Gotzsche PC, Vandenbroucke JP. Strengthening the Reporting of Observational Studies in Epidemiology (STROBE) statement: guidelines for reporting observational studies. BMJ 2007;335:806-8.

25 He K, Liu K, Daviglus ML, Mayer-Davis E, Jenny NS, Jiang R, et al. Intakes of long-chain $\mathrm{n}-3$ polyunsaturated fatty acids and fish in relation to measurements of subclinical atherosclerosis. Am J Clin Nutr 2008;88:1111-8.

26 Mozaffarian D, Lemaitre RN, Kuller LH, Burke GL, Tracy RP, Siscovick DS. Cardiac benefits of fish consumption may depend on the type of fish meal consumed: the Cardiovascular Health Study. Circulation 2003;107:1372-7.

27 Litin L, Sacks F. Trans-fatty-acid content of common foods. N Engl J Med 1993:329:1969-70.

28 Boskou G, Salta FN, Chiou A, Troullidou E, Andrikopoulos NK. Content of trans,trans-2,4-decadienal in deep-fried and pan-fried potatoes. Eur J Lipid Sci Technol 2006;108:109-15.

29 Ansorena D, Guembe A, Mendizabal T, Astiasaran I. Effect of fish and oil nature on frying process and nutritional product quality. J Food Sci 2010;75:H62-7.

30 He K, Liu K, Daviglus ML, Jenny NS, Mayer-Davis E, Jiang R, et al. Associations of dietary long-chain $\mathrm{n}-3$ polyunsaturated fatty acids and fish with biomarkers of inflammation and endothelial activation (from the Multi-Ethnic Study of Atherosclerosis [MESA]). Am J Cardiol 2009;103:1238-43.

31 Williams MJ, Sutherland WH, McCormick MP, de Jong SA, Walker RJ, Wilkins GT. Impaired endothelial function following a meal rich in used cooking fat. J Am Coll Cardiol 1999;33:1050-5.

32 Williams MJ, Sutherland WH, McCormick MP, Yeoman D, de Jong SA, Walker RJ. Normal endothelial function after meals rich in olive or safflower oil previously used for deep frying. Nutr Metab Cardiovasc Dis 2001;11:147-52.

33 Majumder K, Wu J. Angiotensin I converting enzyme inhibitory peptides from simulated in vitro gastrointestinal digestion of cooked eggs. J Agric Food Chem 2009;57:471-7.

34 Echarte M, Ansorena D, Astiasaran I. Fatty acid modifications and cholesterol oxidation in pork loin during frying at different temperatures. J Food Prot 2001;64:1062-6.

35 Sutherland WH, Walker RJ, de Jong SA, van Rij AM, Phillips V, Walker HL. Reduced postprandial serum paraoxonase activity after a meal rich in used cooking fat. Arterioscler Thromb Vasc Biol 1999;19:1340-7.

36 Huerta JM, Tormo MJ, Egea-Caparros JM, Ortola-Devesa JB, Navarro C. Accuracy of self-reported diabetes, hypertension and hyperlipidemia in the adult Spanish population. DINO study findings. Rev Esp Cardiol 2009:62:143-52.

37 Tormo MJ, Navarro C, Chirlaque MD, Barber X. Validation of self diagnosis of high blood pressure in a sample of the Spanish EPIC cohort: overall agreement and predictive values. EPIC Group of Spain. J Epidemiol Community Health 2000;54:221-6.

38 Varela-Moreiras G, Avila JM, Cuadrado C, del Pozo S, Ruiz E, Moreiras O. Evaluation of food consumption and dietary patterns in Spain by the Food Consumption Survey: updated information. Eur J Clin Nutr 2010;64(suppl 3):S37-43.

39 Bach-Faig A, Fuentes-Bol C, Ramos D, Carrasco JL, Roman B, Bertomeu IF, et al. The Mediterranean diet in Spain: adherence trends during the past two decades using the Mediterranean Adequacy Index. Public Health Nutr 2011;14:622-8.

40 Gallina-Toschi T, Cerreteni L, Bendini A, Bonoli-Carbognin M, Lercker G. Oxidative stability and phenolic content of virgin olive oil: an analytical approach by traditional and high resolution techniques. J Sep Sci 2005;28:859-70.

41 Casal S, Malheiro R, Sendas A, Oliveira BPP, Pereira JA. Olive oil stability under deep-frying conditions. Food Chem Toxicol 2010;48:2972-9.

42 Nielsen SJ, Siega-Riz AM, Popkin BM. Trends in energy intake in US between 1977 and 1996: similar shifts seen across age groups. Obes Res 2002;10:370-8.

Accepted: 14 November 2011 


\section{What is already known on this topic}

The consumption of fried food has been associated with some cardiovascular risk factors, such as hypertension, obesity, and low levels of high density lipoprotein cholesterol

The association between fried food consumption and coronary heart disease has been evaluated in some case-control studies, with heterogeneous results

\section{What this study adds}

In Spain, a Mediterranean country that uses olive or sunflower oil for frying, the consumption of fried foods was not associated with risk of coronary heart disease or all cause mortality

Frying with other types of fats, reusing oils several times, or consuming fried snacks high in salt may still be harmful

\section{Cite this as: BMJ 2012;344:e363}

This is an open-access article distributed under the terms of the Creative Commons Attribution Non-commercial License, which permits use, distribution, and reproduction in any medium, provided the original work is properly cited, the use is non commercial and is otherwise in compliance with the license. See: http://creativecommons.org/licenses/bync/2.0/ and http://creativecommons.org/licenses/by-nc/2.0/legalcode. 


\section{Tables}

Table 1 | Consumption of fried foods, sociodemographic variables, and lifestyles of study participants at baseline, by quarters of fried food consumption. Values are means unless stated otherwise

\begin{tabular}{|c|c|c|c|c|}
\hline \multirow[b]{2}{*}{ Characteristics } & \multicolumn{4}{|c|}{ Quarters of fried food consumption } \\
\hline & 1 (lowest) & 2 & 3 & 4 (highest) \\
\hline \multicolumn{5}{|l|}{ Consumption of fried foods } \\
\hline Total amount of fried food consumed ( $\mathrm{g} /$ day) & 47.0 & 105.7 & 158.4 & 249.6 \\
\hline Fried fish (g/day) & 12.6 & 28.8 & 40.6 & 53.6 \\
\hline Fried meat ( $\mathrm{g} /$ day) & 8.3 & 21.7 & 36.2 & 59.9 \\
\hline Fried potatoes (g/day) & 9.3 & 21.6 & 33.3 & 57.7 \\
\hline Fried eggs (g/day) & 4.0 & 10.7 & 17.1 & 28.0 \\
\hline \multicolumn{5}{|l|}{ Sociodemographic variables } \\
\hline Age (years) & 50.4 & 49.5 & 48.9 & 48.3 \\
\hline \multicolumn{5}{|l|}{ Educational level (\%): } \\
\hline No formal education & 41.9 & 36.4 & 31.7 & 27.6 \\
\hline Primary education & 31.6 & 35.9 & 40.8 & 46.6 \\
\hline Secondary education & 12.6 & 14.2 & 16.0 & 16.0 \\
\hline University education & 13.3 & 12.8 & 10.8 & 9.0 \\
\hline \multicolumn{5}{|l|}{ Lifestyle } \\
\hline \multicolumn{5}{|l|}{ Smoking (\%): } \\
\hline Never smoker & 58.3 & 59.3 & 59.5 & 59.7 \\
\hline Current smoker & 22.5 & 22.5 & 23.7 & 24.2 \\
\hline Former smoker & 19.2 & 18.2 & 16.8 & 16.1 \\
\hline \multicolumn{5}{|l|}{ Physical activity at work (\%): } \\
\hline Sedentary & 22.8 & 22.1 & 20.4 & 18.8 \\
\hline Standing & 62.1 & 64.2 & 63.7 & 63.4 \\
\hline Manual labour & 6.2 & 8.5 & 10.3 & 12.3 \\
\hline Heavy manual labour & 2.2 & 1.9 & 2.1 & 2.5 \\
\hline Does not work & 3.8 & 3.3 & 3.6 & 3.1 \\
\hline Physical activity at home (METs h/week) & 68.6 & 69.8 & 70.0 & 68.1 \\
\hline Physical activity in leisure time (METs h/week) & 28.7 & 28.2 & 28.6 & 28.4 \\
\hline
\end{tabular}

MET=metabolic equivalents. Range of quarters of fried food consumption in g/day for men: first quarter (0-112), second quarter (113-176), third quarter (177-246), and fourth quarter (247-817), and for women: first quarter (0-59), second quarter (60-103), third quarter (104-154), and fourth quarter (155-657). 
Table 2| Morbidity, menopausal status, use of hormone treatment, consumption of non-fried food, and potential mediators of study association among study participants at baseline, by quarters of fried food consumption. Values are means unless stated otherwise

\begin{tabular}{|c|c|c|c|c|}
\hline \multirow[b]{2}{*}{ Characteristics } & \multicolumn{4}{|c|}{ Quarters of fried food consumption } \\
\hline & 1 (lowest) & 2 & 3 & 4 (highest) \\
\hline \multicolumn{5}{|l|}{ Diseases diagnosed: } \\
\hline Diabetes mellitus (\%) & 7.5 & 5.1 & 3.9 & 3.2 \\
\hline Hyperlipidaemia (\%) & 24.8 & 20.5 & 18.5 & 16.7 \\
\hline Cancer (\%) & 1.0 & 0.9 & 0.8 & 0.8 \\
\hline Menopause $(\%)^{*}$ & 42.2 & 36.9 & 33.0 & 29.3 \\
\hline \multicolumn{5}{|l|}{ Hormone treatment $(\%)^{*}:$} \\
\hline Oral contraceptives & 24.7 & 26.4 & 26.6 & 27.4 \\
\hline Hormone substitution therapy & 6.4 & 6.2 & 5.5 & 5.6 \\
\hline \multicolumn{5}{|c|}{ Other nutrients and foods consumed: } \\
\hline Total energy (kcal/day) & 1920.1 & 2133.0 & 2294.8 & 2566.6 \\
\hline Ethanol (g/day) & 11.5 & 14.5 & 17.0 & 20.4 \\
\hline Non-fried vegetables (g/day) & 255.0 & 241.1 & 232.3 & 237.4 \\
\hline Fruit (g/day) & 336.6 & 322.0 & 315.3 & 311.2 \\
\hline Dried fruit and nuts (g/day) & 5.0 & 4.6 & 4.2 & 3.9 \\
\hline Milk products (g/day) & 304.7 & 298.1 & 296.9 & 292.0 \\
\hline Non-fried meat (g/day) & 93.9 & 98.0 & 97.9 & 96.2 \\
\hline Non-fried fish (g/day) & 37.2 & 29.6 & 26.0 & 23.8 \\
\hline \multicolumn{5}{|l|}{ Mediators of study association: } \\
\hline Body mass index $\left(\mathrm{kg} / \mathrm{m}^{2}\right)$ & 28.5 & 28.3 & 28.1 & 28.1 \\
\hline Waist circumference $(\mathrm{cm})$ & 92.8 & 92.0 & 91.4 & 91.4 \\
\hline Hypertension (\%) & 23.7 & 20.9 & 18.4 & 17.4 \\
\hline
\end{tabular}

See table 1 for range (g/day) of quarters of fried food consumption for men and for women.

${ }^{*}$ Calculated for women. 
Table 3| Association between fried food consumption and incidence of definite coronary heart disease and all cause mortality during 11 years of follow-up in Spanish cohort of European Prospective Investigation into Cancer and Nutrition

\begin{tabular}{|c|c|c|c|c|c|c|}
\hline \multirow[b]{2}{*}{ Variables } & \multicolumn{4}{|c|}{ Quarters of fried food consumption } & \multirow[b]{2}{*}{$P$ for trend } & \multirow{2}{*}{$\begin{array}{c}\text { For } 100 \mathrm{~g} \text { increase } \\
\text { of fried food }\end{array}$} \\
\hline & 1 (lowest) & 2 & 3 & 4 (highest) & & \\
\hline \multicolumn{7}{|l|}{ Coronary heart disease: } \\
\hline Total No & 10188 & 10190 & 10190 & 10189 & & \\
\hline Person years & 109578 & 110394 & 110943 & 111762 & & \\
\hline No of events & 154 & 163 & 150 & 139 & & \\
\hline $\begin{array}{l}\text { Model } 1^{*}: \text { hazard ratios } \\
(95 \% \mathrm{Cl})\end{array}$ & 1 & 1.05 (0.84 to 1.33$)$ & $0.97(0.76$ to 1.24$)$ & $0.94(0.72$ to 1.23$)$ & 0.52 & 0.95 (0.86 to 1.06$)$ \\
\hline $\begin{array}{l}\text { Model } 2 \dagger \text { : hazard ratios } \\
(95 \% \mathrm{Cl})\end{array}$ & 1 & 1.15 (0.91 to 1.46$)$ & $1.08(0.84$ to 1.39$)$ & $1.11(0.84$ to 1.46$)$ & 0.60 & 1.01 (0.91 to 1.12$)$ \\
\hline $\begin{array}{l}\text { Model 3\$: hazard ratios } \\
(95 \% \mathrm{Cl})\end{array}$ & 1 & 1.15 (0.91 to 1.45$)$ & $1.07(0.83$ to 1.38$)$ & $1.08(0.82$ to 1.43$)$ & 0.74 & $1.00(0.90$ to 1.11$)$ \\
\hline \multicolumn{7}{|l|}{ All cause mortality: } \\
\hline Total No & 10188 & 10190 & 10190 & 10189 & & \\
\hline Person years & 110135 & 111019 & 111560 & 112342 & & \\
\hline No of deaths & 328 & 276 & 273 & 258 & & \\
\hline $\begin{array}{l}\text { Model } 1^{*} \text { : hazard ratios } \\
(95 \% \mathrm{Cl})\end{array}$ & 1 & 0.90 (0.76 to 1.07$)$ & 0.91 (0.77 to 1.09$)$ & 0.89 (0.73 to 1.08$)$ & 0.26 & 0.98 (0.91 to 1.06$)$ \\
\hline $\begin{array}{l}\text { Model 2†: hazard ratios } \\
(95 \% \mathrm{Cl})\end{array}$ & 1 & $0.94(0.79$ to 1.11$)$ & 0.95 (0.80 to 1.14$)$ & $0.94(0.77$ to 1.15$)$ & 0.60 & $1.00(0.92$ to 1.08$)$ \\
\hline $\begin{array}{l}\text { Model 3¥: hazard ratios } \\
(95 \% \mathrm{Cl})\end{array}$ & 1 & 0.94 (0.79 to 1.11$)$ & 0.95 (0.79 to 1.13$)$ & $0.93(0.77$ to 1.14$)$ & 0.98 & 1.00 (0.92 to 1.08$)$ \\
\hline
\end{tabular}

Quarters are sex specific. See table 1 for range ( $g /$ day) of quarters of fried food consumption for men and for women.

*Adjusted for age, sex, centre (Asturias, Gipuzkoa, Granada, Murcia, or Navarra), and energy intake (quarters).

†Adjusted for variables in model 1 and for ethanol consumption (quarters among consumers), educational level (no formal education, primary, vocational, secondary, university education), smoking (never, current, former), physical activity at work (sedentary, standing, manual labour, heavy manual labour, no work), physical activity at home (metabolic equivalents $\mathrm{h} /$ week in quarters), physical activity in leisure time (metabolic equivalents h/week in quarters), diabetes mellitus, hyperlipidaemia, cancer, oral contraceptives, menopause, hormone replacement therapy, and consumption of fruit (quarters), nuts (quarters), and dairy products (quarters), and non-fried foods (quarters): vegetables, meat, and fish.

$\ddagger$ Adjusted for variables in model 2 and for body mass index ( $<25$ and $\geq 25,<30$ and $\geq 30,<35$ and $\geq 35$ ), waist circumference (quarters), and hypertension. 
Table 4| Association between consumption of main types of fried food and incidence of definite coronary heart disease and all cause mortality during 11 years of follow-up in Spanish cohort of European Prospective Investigation into Cancer and Nutrition

\begin{tabular}{|c|c|c|c|c|c|c|}
\hline \multirow[b]{2}{*}{ Variables } & \multicolumn{4}{|c|}{ Quarters of fried food consumption } & \multirow[b]{2}{*}{$P$ for trend } & \multirow{2}{*}{$\begin{array}{l}\text { For } 100 \mathrm{~g} \text { increase } \\
\text { of fried food }\end{array}$} \\
\hline & 1 (lowest) & 2 & 3 & 4 (highest) & & \\
\hline \multicolumn{7}{|l|}{ Coronary heart disease } \\
\hline \multicolumn{7}{|l|}{ Fried fish: } \\
\hline No of events & 144 & 136 & 149 & 177 & - & - \\
\hline Hazard ratio $(95 \% \mathrm{Cl})^{*}$ & 1 & 0.99 (0.78 to 1.26$)$ & $1.06(0.83$ to 1.35$)$ & $1.13(0.89$ to 1.44$)$ & 0.26 & $1.03(0.82$ to 1.29$)$ \\
\hline \multicolumn{7}{|l|}{ Fried meat: } \\
\hline No of events & 137 & 158 & 174 & 137 & - & - \\
\hline Hazard ratio $(95 \% \mathrm{Cl})^{\star}$ & 1 & $1.17(0.93$ to 1.49$)$ & $1.40(1.09$ to 1.79$)$ & 1.09 (0.82 to 1.43$)$ & 0.32 & $1.05(0.82$ to 1.35$)$ \\
\hline \multicolumn{7}{|l|}{ Fried potatoes: } \\
\hline No of events & 188 & 151 & 138 & 129 & - & - \\
\hline Hazard ratio $(95 \% \mathrm{Cl})^{*}$ & 1 & $0.92(0.74$ to 1.15$)$ & $0.95(0.75$ to 1.19$)$ & $0.90(0.70$ to 1.15$)$ & 0.45 & $0.91(0.71$ to 1.17$)$ \\
\hline \multicolumn{7}{|l|}{ Fried eggs: } \\
\hline No of events & 184 & 151 & 145 & 126 & - & - \\
\hline Hazard ratio $(95 \% \mathrm{Cl})^{*}$ & 1 & 0.99 (0.80 to 1.24$)$ & $0.95(0.76$ to 1.20$)$ & 0.87 (0.68 to 1.13$)$ & 0.30 & $0.84(0.51$ to 1.40$)$ \\
\hline \multicolumn{7}{|l|}{ All cause mortality } \\
\hline \multicolumn{7}{|l|}{ Fried fish: } \\
\hline No of events & 297 & 276 & 271 & 291 & - & - \\
\hline Hazard ratio $(95 \% \mathrm{Cl})^{*}$ & 1 & $0.99(0.84$ to 1.17$)$ & $0.97(0.81$ to 1.15$)$ & $0.92(0.77$ to 1.10$)$ & 0.34 & $0.84(0.69$ to 1.01$)$ \\
\hline \multicolumn{7}{|l|}{ Fried meat: } \\
\hline No of events & 346 & 246 & 264 & 279 & - & - \\
\hline Hazard ratio $(95 \% \mathrm{Cl})^{\star}$ & 1 & 0.80 (0.67 to 0.95$)$ & $0.90(0.75$ to 1.08$)$ & $0.94(0.78$ to 1.14$)$ & 0.72 & $0.96(0.79$ to 1.16$)$ \\
\hline \multicolumn{7}{|l|}{ Fried potatoes: } \\
\hline No of events & 353 & 273 & 249 & 260 & - & - \\
\hline Hazard ratio $(95 \% \mathrm{Cl})^{\star}$ & 1 & $0.90(0.77$ to 1.06$)$ & $0.92(0.78$ to 1.09$)$ & $0.99(0.83$ to 1.18$)$ & 0.87 & $1.10(0.91$ to 1.32$)$ \\
\hline \multicolumn{7}{|l|}{ Fried eggs: } \\
\hline No of events & 350 & 265 & 245 & 275 & - & - \\
\hline Hazard ratio $(95 \% \mathrm{Cl})^{*}$ & 1 & 0.96 (0.81 to 1.13$)$ & $0.90(0.75$ to 1.06$)$ & 1.05 (0.87 to 1.25$)$ & 0.90 & $1.11(0.76$ to 1.64$)$ \\
\hline
\end{tabular}

*Adjusted the same as model 3 in table 3.

Range of quarters of fried food consumption in g/day: fish consumption for men: first quarter (0-15), second quarter (16-35), third quarter (36-61), and fourth quarter (62-439), and for women: first quarter (0-8), second quarter (9-23), third quarter (24-40), and fourth quarter (41-346); meat consumption for men: first quarter (0-12), second quarter (13-34), third quarter (35-65), and fourth quarter (66-384), and for women: first quarter (0-2), second quarter (3-15), third quarter (16-36), and fourth quarter (37-347); potato consumption for men: first quarter (0-12), second quarter (13-33), third quarter (34-59), fourth quarter (60-560), and for women: first quarter (0-3), second quarter (4-17), third quarter (18-34), and fourth quarter (35-282); egg consumption for men: first quarter (0-6), second quarter (7-15), third quarter (16-30), fourth quarter (31-176), and for women: first quarter (0-0), second quarter (1-8), third quarter (9-17), and fourth quarter (18-123). 